\title{
Prospective relation between catastrophizing and residual pain following knee arthroplasty: Two-year follow-up
}

\author{
Michael E Forsythe MD ${ }^{1}$, Michael J Dunbar MD FRCS PhD ${ }^{2}$, Allan W Hennigar BSc $^{2}$, Michael JL Sullivan PhD ${ }^{3}$,
} Michael Gross MD FRCS ${ }^{2}$

\begin{abstract}
ME Forsythe, MJ Dunbar, AW Hennigar, MJL Sullivan, M Gross. Prospective relation between catastrophizing and residual pain following knee arthroplasty: Two-year follow-up. Pain Res Manage 2008;13(4):335-341.
\end{abstract}

BACKGROUND: Pain is the primary indication for both primary and revision total knee arthroplasty (TKA); however, most arthroplasty outcome measures do not take pain into account.

OBJECTIVE: To document the prospective pain experience following TKA, with subjective pain-specific questionnaires to determine if comorbidities, preoperative pain or preoperative pain catastrophizing scores are predictive of long-term pain outcomes.

METHODS: Fifty-five patients with a primary diagnosis of osteoarthritis of the knee, who were scheduled to undergo TKA, were asked to fill out the McGill Pain Questionnaire (MPQ) and the Pain Catastrophizing Scale (PCS) preoperatively and at three, 12 and 24 months follow-up. Comorbidities were extracted from the Queen Elizabeth II Health Sciences Centre health information system.

RESULTS: The overall response rate (return of completed questionnaires) was $84 \%$. There was a significant decrease in the MPQ scores $(\mathrm{P}<0.05)$ postoperatively. PCS scores did not change over time. Receiver operating characteristic curves revealed the number of comorbidities per patient predicted the presence of pain postoperatively, as documented by the numerical rating subscale of the MPQ at 24 months $(\mathrm{P}<0.05)$. Receiver operating characteristic curves for preoperative PCS and rumination subscale scores predicted the presence of pain, as measured by the Pain Rating Index subscale of the MPQ at 24 months $(\mathrm{P}<0.05)$. Preoperative PCS scores and comorbidities were significantly higher in the persistent pain group $(\mathrm{P}<0.05)$.

CONCLUSIONS: The number of comorbidities predicted the presence of pain at 24 months follow-up and, for the first time, preoperative PCS scores were shown to predict chronic postoperative pain. This may enable the identification of knee arthroplasty patients at risk for persistent postoperative pain, thus allowing for efficient administration of preoperative interventions to improve arthroplasty outcomes.

Key Words: Catastrophizing, Comorbidity, Helplessness, Knee, Osteoarthritis, Outcomes, Pain, Rumination, Surgery, Total knee arthroplasty

\section{Une relation prospective entre la dramatisation de la douleur et la douleur résiduelle après une arthroplastie du genou : Un suivi de deux ans}

HISTORIQUE : La douleur est l'indication primaire d'arthroplastie totale du genou (ATG) primaire et de reprise, mais la plupart des mesures d'issue de l'arthroplastie ne tiennent pas compte de la douleur.

OBJECTIF : Documenter l'expérience de douleur prospective après une ATG au moyen de questionnaires portant sur la douleur subjective, pour déterminer si les comorbidités, la douleur préopératoire ou les indices de dramatisation de la douleur préopératoire sont prédictifs des issues de douleur à long terme.

MÉTHODOLOGIE : Cinquante-cinq patients ayant un diagnostic primaire d'arthrose du genou qui devaient subir une ATG ont été invités à remplir le questionnaire de la douleur de McGill (QDM) et l'échelle de dramatisation de la douleur (ÉDD) avant l'opération et au suivi trois, 12 et 24 mois après l'opération. Les auteurs ont extrait les comorbidités du système d'information en santé du Queen Elizabeth II Health Sciences Centre.

RÉSULTATS : Le taux de réponse global (retour des questionnaires remplis) était de $84 \%$. Les auteurs ont constaté une diminution marquée des indices du QDM $(\mathrm{P}<0,05)$ après l'opération. Les indices de l'ÉDD n'ont pas changé au fil du temps. Les courbes de fonction d'efficacité du récepteur ont révélé que le nombre de comorbidités dont avait souffert chaque patient était prédictif de la présence de douleur postopératoire, documentée par la sous-échelle d'évaluation chiffrée du QDM au suivi de 24 mois $(\mathrm{P}<0,05)$. Les courbes de fonction d'efficacité du récepteur pour l'ÉDD préopératoire et les indices de sous-échelle de rumination étaient prédictifs de la présence de douleur, mesurée par la sous-échelle d'indice d'évaluation de la douleur du QDM à 24 mois $(\mathrm{P}<0,05)$. Les indices d'ÉDD préopératoires et les comorbidités étaient considérablement plus élevées dans le groupe de douleur persistante $(\mathrm{P}<0,05)$.

CONCLUSIONS : Le nombre de comorbidités était prédictif de la présence de douleur au suivi de 24 mois et, pour la première fois, il était démontré que les indices d'ÉDD préopératoires étaient prédictifs de la douleur postopératoire. Ce phénomène pourrait permettre de repérer les patients subissant une arthroplastie du genou vulnérables à une douleur postopératoire persistante, ce qui assurerait l'administration efficace des interventions préopératoires afin d'améliorer les issues de l'arthroplastie.

\footnotetext{
A rthritis is the leading cause of disability in North America (1). Osteoarthritis (OA) is the most common form of arthritis, affecting approximately 21 million people in the United States and three2 million people in Canada $(1,2)$. In
}

advanced stages of the disease, joint deterioration can lead to significant pain and limitations of function. Patients with severe symptomatic OA of the knee may be considered candidates for knee replacement surgery (total knee arthroplasty

${ }^{1}$ Division of Orthopedic Surgery, Moncton Hospital, South-East Regional Health Authority, Moncton, New Brunswick; ${ }^{2}$ Division of Orthopedic

Surgery, Queen Elizabeth II Health Sciences Centre and Dalhousie University, Halifax, Nova Scotia; ${ }^{3}$ Department of Psychology, McGill

University, Montreal, Quebec

Correspondence: Dr Michael J Dunbar, Department of Surgery, Queen Elizabeth II Health Sciences Centre, Suite 4822, Halifax Infirmary,

1796 Summer Street, Halifax, Nova Scotia B3H 3A7. Telephone 902-473-7337, fax 902-473-7370 
[TKA]). Although TKA yields significant benefits, research suggests that $13 \%$ to $30 \%$ of patients will have a problematic course of recovery, characterized by prolonged and intense pain, mobility restriction, disability and reduced quality of life $(3,4)$. Problems often persist in spite of objective indications of surgical success (5). The present research examined the prognostic value of preoperative pain catastrophizing in the prediction of long-term pain outcomes.

\section{Outcome of TKA}

As a result of advances in prosthetic design and in surgical technique, TKA has resulted in improved function, pain relief and quality of life for many patients who would have otherwise endured significant and prolonged distress and disability (6). Although surgical indications vary among surgeons, prolonged pain that is refractory to nonsurgical management is the primary indication for surgery (7). Nonsurgical measures include nonsteroidal anti-inflammatory drugs, acetaminophen, steroid injections, glucosamine, physiotherapy and bracing (8). Once the pain leads to significant disability, surgery becomes an option. Because the average lifespan of primary TKA is 10 to 15 years, it is preferable to wait until the patient is older than 55 years of age to offer surgery.

The reduction in pain following knee arthroplasty leads to improved function and quality of life (6). Pain is reduced as the arthritic cartilage and subchondral bone are replaced with metal surfaces separated by a polyethylene spacer between the femoral and tibial components (9). Reduction in pain following TKA is considered to be the primary determinant of patients' satisfaction with surgery $(4,10)$.

Outcome analysis is an accepted method for measuring the results of TKA, and much effort has been directed toward developing appropriate questionnaires for evaluating it (10). Objective surgeon-derived measurement tools have been shown to be biased and unreliable, and have spawned the development of subjective questionnaires (11). The Shortform 36 (SF-36) and Short-form 12 (SF-12) Health Surveys, the Western Ontario and McMaster Universities Osteoarthritis Index and the Oxford 12-item Knee Score are well validated; however, none of these metrics exclusively document the pain experience of the patient (10).

Because pain experience guides clinical outcomes and surgical intervention, including revisions, further understanding of postsurgical pain is important for improving outcomes (5). There are indications that for a significant proportion of patients, pain symptoms may persist well beyond the normal recovery period after TKA (3). Efforts to uncover the medical basis of these persistent pain symptoms have yielded inconsistent or inconclusive findings $(12,13)$. It is clear, however, that regardless of etiology, persistent pain symptoms following surgery can adversely affect function and quality of life $(14,15)$. If it were possible to identify patients at risk for the development of persistent pain following TKA, preventative interventions or more aggressive pain management could be initiated to minimize the probability of long-term distress and disability.

\section{Catastrophizing and pain experience}

Research over the past three decades has highlighted the importance of psychological factors as contributors to pain experience (16-18). Research attention turned to psychological variables associated with pain when it became evident that physical variables accounted only for modest variance in pain outcomes $(19,20)$. The term 'pain catastrophizing' has been used to describe a response style to painful experiences that is likely to be associated with negative pain outcomes (21). Pain catastrophizing is characterized by a tendency to focus excessively on pain sensations (ie, rumination), to exaggerate the threat value of pain sensations (ie, magnification) and to perceive oneself as being unable to control pain symptoms (ie, helplessness) (22). Recent reviews of the literature have identified pain catastrophizing as one of the most robust psychological predictors of pain experience $(22,23)$. A relation between catastrophizing and pain intensity was demonstrated in more than 600 studies across a wide range of clinical and experimental conditions $(22,24)$.

Although the relation between catastrophizing and pain experience has been shown to be robust, the prognostic value of measures of catastrophizing for the development of chronic pain following TKA has not been systematically investigated. The majority of studies conducted to date have been crosssectional in design (19). As such, whether catastrophizing is an 'antecedent' or 'consequence' of heightened pain experience following TKA cannot be determined with any certainty.

Roth et al (25) recently reported on the prognostic value of a measure of catastrophizing for perioperative pain following TKA. In the latter study, catastrophizing was assessed the day before surgery and was used to predict pain severity during the first three days following surgery. Although significant relations between catastrophizing and pain emerged 'within' each test point, preoperative pain catastrophizing did not predict postoperative pain (25). It is possible that the effects of pain medication, which are likely to be administered to a significant degree in the period immediately following surgery, may have obscured the relation between presurgical catastrophizing and postoperative pain.

There is a basis nevertheless for considering that catastrophizing may predict long-term or chronic pain. Research on health outcomes associated with musculoskeletal conditions supported the prognostic role of catastrophizing for the development of chronic pain $(23,26-28)$. There is also a growing amount of literature reporting that the determinants of acute postsurgical pain may differ in important ways from the determinants of chronic pain (29-31). It is possible that the adverse effects of catastrophizing on pain experience following TKA may only emerge over an extended period of time.

In the present study, patients scheduled for TKA with a primary diagnosis of $\mathrm{OA}$ were asked to complete a measure of catastrophizing and pain before surgery, and again at three, 12 and 24 months postoperatively. The primary questions addressed by the present research were whether preoperative pain, preoperative catastrophizing scores and comorbidities predicted the persistence of long-term pain symptoms following surgery.

\section{Participants}

\section{METHODS}

After appropriate ethics board approval, 55 consecutive patients booked for elective TKA agreed to participate in the presesnt study between January 1999 and January 2000, at the Queen Elizabeth II Health Sciences Centre in Halifax, Nova Scotia. Seventy patients were approached for the study, yielding an approximate enrollment rate of $79 \%$. The mean age of the patient sample was 69.0 years, with a range of 49 to 
TABLE 1

Patient demographic variables

\begin{tabular}{lcc}
\hline & Men $\mathbf{( n = 2 0 )}$ & Women $\mathbf{( n = 3 5 )}$ \\
\hline Age, years & $70.0 \pm 7.2$ & $68.5 \pm 8.9$ \\
Length of stay, days & $5.9 \pm 1.4$ & $5.5 \pm 1.6$ \\
Comorbidities $^{*}, \mathrm{n}$ & $2.6 \pm 1.4$ & $1.6 \pm 1.3$ \\
Spinal anesthesia, $\mathrm{n}(\%)$ & $10(50)$ & $17(49)$ \\
General anesthesia, $\mathrm{n}(\%)$ & $10(50)$ & $18(51)$
\end{tabular}

Results presented as mean $\pm S D$ unless otherwise stated. ${ }^{*}$ Denotes significant difference $(P<0.05)$ between sexes

85 years; there were 35 women (64\%) and 20 men (36\%). Male and female age distributions were similar.

\section{Measures}

Catastrophizing: The Pain Catastrophizing Scale (PCS [21]) was used to assess catastrophic thinking associated with pain. On the PCS, participants rate how frequently they experience each of 13 thoughts or feelings while they are in pain. Ratings are made on five-point scales, with the end points being 0 (not at all) and 4 (all the time). The PCS yields a total score (PCS$\mathrm{T})$ and three subscale scores assessing rumination (PCS-R), magnification (PCS-M) and helplessness (PCS-H). The PCS subscales were shown to have adequate to high internal consistency (Cronbach's alphas: PCS-T, 0.87; PCS-R, 0.87; PCS-M, 0.66; and PCS-H, 0.78) (21).

Pain: The McGill Pain Questionnaire (MPQ) consists of 15 adjectives describing sensory, affective and evaluative aspects of pain experience. Patients rate the adjectives (Pain Rating Index [PRI]) that best describe their current pain with a four-point scale, with end points of 0 (none) and 3 (severe) (32). Patients also rate their present pain intensity on a visual analogue scale (VAS) and the overall intensity of their total pain experience on a numerical rating scale, with the end points 0 (no pain) and 5 (excruciating pain).

Comorbidities: Comorbidities for each patient were extracted from the charts and coded using the International Classification of Diseases, 9th revision, Clinical Modification (ICD-9) system. Data were then obtained from the Queen Elizabeth II Health Sciences Centre database. The most common comorbidities included OA of the lower limbs, hypertension, history of tobacco use and diabetes mellitus. Examples of other conditions less frequently reported were obesity, hypothyroidism, ischemic heart disease, depression and cardiovascular disease. Only the absolute number of comorbidities was used as a variable, and there was no attempt to qualify the actual contribution to pain from each comorbidity for each patient.

\section{Procedure}

After appropriate consent, participants were asked to complete the PCS and the MPQ, along with a standard medical history and physical examination, in the same-day surgery clinic approximately one week before surgery. Postoperatively, patients were mailed a copy of each questionnaire at three, 12 and 24 months, along with a self-addressed stamped envelope. A reminder letter with repeat questionnaires was sent out after two weeks if the questionnaires were not returned. Patients were asked to fill out the questionnaires in relation to the operative knee only, because many patients had multiple previously treated joints.
TABLE 2

Preoperative and postoperative McGill Pain Questionnaire scores

\begin{tabular}{lcccc}
\hline & $\begin{array}{c}\text { Preoperative } \\
(\mathbf{n}=55)\end{array}$ & $\begin{array}{c}\text { Follow-up } \\
\mathbf{3} \text { months } \\
(\mathbf{n = 4 3 )}\end{array}$ & $\begin{array}{c}\text { Follow-up } \\
\mathbf{1 2} \text { months } \\
\mathbf{( n = 4 6 )}\end{array}$ & $\begin{array}{c}\text { Follow-up } \\
\mathbf{2 4} \text { months } \\
(\mathbf{n}=\mathbf{4 8})\end{array}$ \\
\hline Pain Rating Index & $17.8 \pm 8.1^{*}$ & $10.1 \pm 8.3$ & $8.4 \pm 9.3$ & $7.6 \pm 8.7$ \\
Visual analogue scale & $6.8 \pm 1.9^{*}$ & $3.3 \pm 2.7$ & $2.7 \pm 3.0$ & $2.2 \pm 2.3$ \\
Present pain intensity & $2.9 \pm 1.1^{*}$ & $1.5 \pm 1.2$ & $1.2 \pm 1.1$ & $1.1 \pm 1.0$
\end{tabular}

Results presented as mean $\pm S D$. *Denotes significant difference $(P<0.05)$ from other time periods using Bonferroni post hoc tests

TABLE 3

Preoperative and postoperative Pain Catastrophizing Scale scores

\begin{tabular}{lcccc}
\hline & $\begin{array}{c}\text { Preoperative } \\
(\mathbf{n}=55)\end{array}$ & $\begin{array}{c}\text { Follow-up } \\
\mathbf{3} \text { months } \\
(\mathbf{n}=\mathbf{4 3})\end{array}$ & $\begin{array}{c}\text { Follow-up } \\
\mathbf{1 2} \text { months } \\
(\mathbf{n}=\mathbf{4 6})\end{array}$ & $\begin{array}{c}\text { Follow-up } \\
\mathbf{2 4} \text { months } \\
(\mathbf{n}=\mathbf{4 8})\end{array}$ \\
\hline PCS-R & $5.0 \pm 3.3$ & $4.3 \pm 3.5$ & $4.0 \pm 4.5$ & $4.5 \pm 4.0$ \\
PCS-M & $1.4 \pm 2.1$ & $1.8 \pm 1.9$ & $1.7 \pm 2.0$ & $2.1 \pm 2.1$ \\
PCS-H & $3.4 \pm 4.7$ & $3.6 \pm 3.6$ & $3.2 \pm 3.9$ & $3.1 \pm 4.3$ \\
PCS-T & $9.8 \pm 8.7$ & $10.0 \pm 8.2$ & $8.8 \pm 9.6$ & $9.8 \pm 9.3$ \\
\hline
\end{tabular}

Results presented as mean $\pm S D$. PCS-H Pain Catastrophizing Scale Helplessness; PCS-M Pain Catastrophizing Scale - Magnification; PCS-R Pain Catastrophizing Scale - Rumination; PCS-T Pain Catastrophizing Scale - Total

All data obtained from the questionnaires, along with personal data from the hospital database, were placed in a Microsoft Office Excel version 4.0 (Microsoft Canada Co) spreadsheet, and analyzed using SPSS version 9.0 (SPSS Inc, USA). Preoperative and postoperative scores were compared using ANOVA Bonferroni post hoc tests. Predictive statistics were performed using receiver operating characteristic (ROC) curves to determine which preoperative variables predicted the long-term pain outcomes. Those patients with persistent pain were compared with those patients with no pain at 24 months, using the Mann-Whitney $U$ test for nonparametric data. A $\mathrm{P}<0.05$ was used as the level of significance.

Response rate

\section{RESULTS}

The two questionnaires used in the present study were selfadministered and mailed out. Of the initial 55 patients who filled out the questionnaire preoperatively, $49(89 \%)$ returned them filled out at three months, of which 43 (88\%) were complete. At 12 months, 51 (93\%) of the questionnaires were filled out, of which 46 (90\%) were complete. At 24 months, $52(95 \%)$ of the patients filled out questionnaires, of which 48 (92\%) were complete.

\section{Descriptive statistics}

Mean scores for age, length of stay and comorbidities are presented in Table 1. The patients' mean age was 69 years, mean length of stay was six days and mean number of comorbidities was two. Twenty-seven (49\%) of 55 patients underwent spinal anesthesia and 28 (51\%) underwent general anesthesia. There were no differences among any of the outcome measures as a function of type of anesthesia (spinal versus general). Preoperative and postoperative MPQ scores are presented in Table 2. Preoperative and follow-up catastrophizing scores are presented in Table 3. 


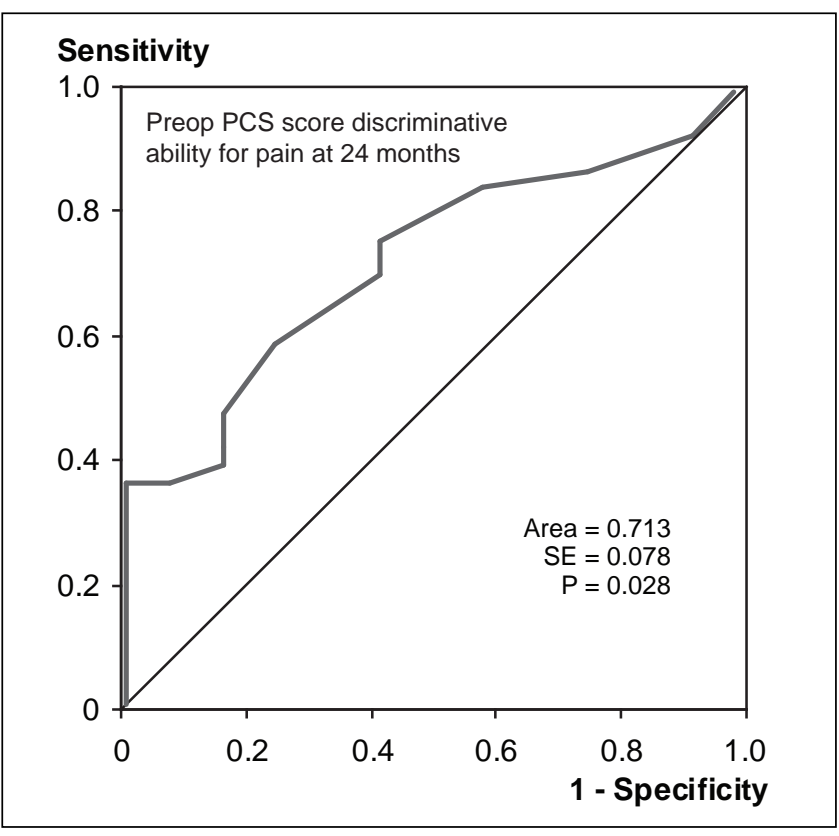

Figure 1) Receiver operating characteristic curve indicating the ability of the preoperative (preop) total catastrophizing scores (Pain Catastrophizing Scale [PCS]) to discriminate between patients with pain (n=36) and no pain $(n=12)$ at 24 months after surgery, as reported on the Pain Rating Index (McGill Pain Questionnaire)

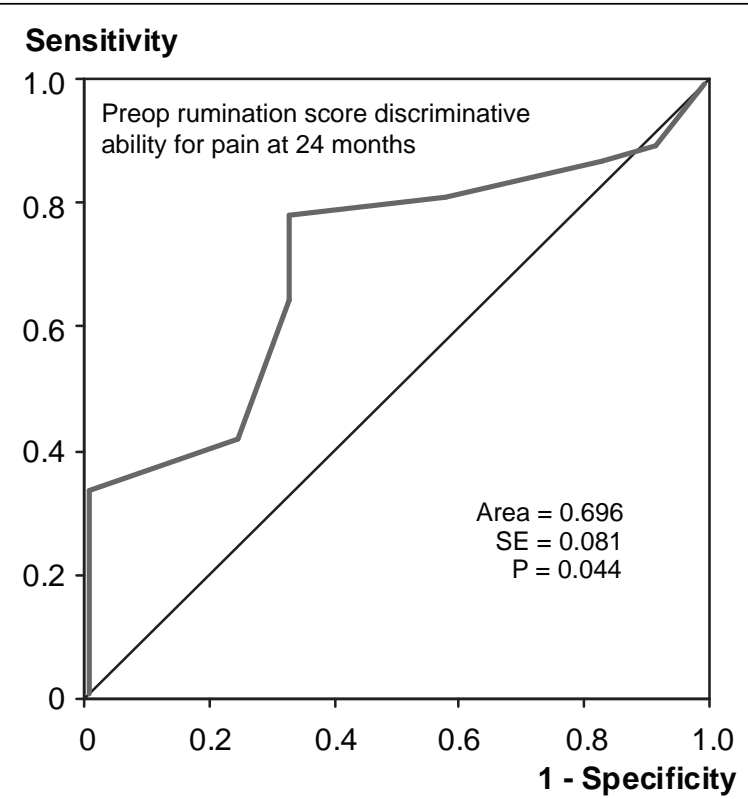

Figure 2) Receiver operating characteristic curve indicating the ability of preoperative (preop) rumination scores to discriminate between patients with pain $(n=36)$ and no pain $(n=12)$ at 24 months after surgery, as reported on the Pain Rating Index (McGill Pain Questionnaire)

Using repeated measures ANOVA tests, a statistically significant decrease was found in both the mean PRI scores and VAS scores from the preoperative time period, compared with the follow-up time period at three, 12 and 24 months, respectively $(\mathrm{P}<0.01)$. The mean preoperative $\mathrm{PRI}$ score was 17.8 , which decreased to 10.1 after three months, 8.4 after 12 months and 7.6 after 24 months. The mean preoperative

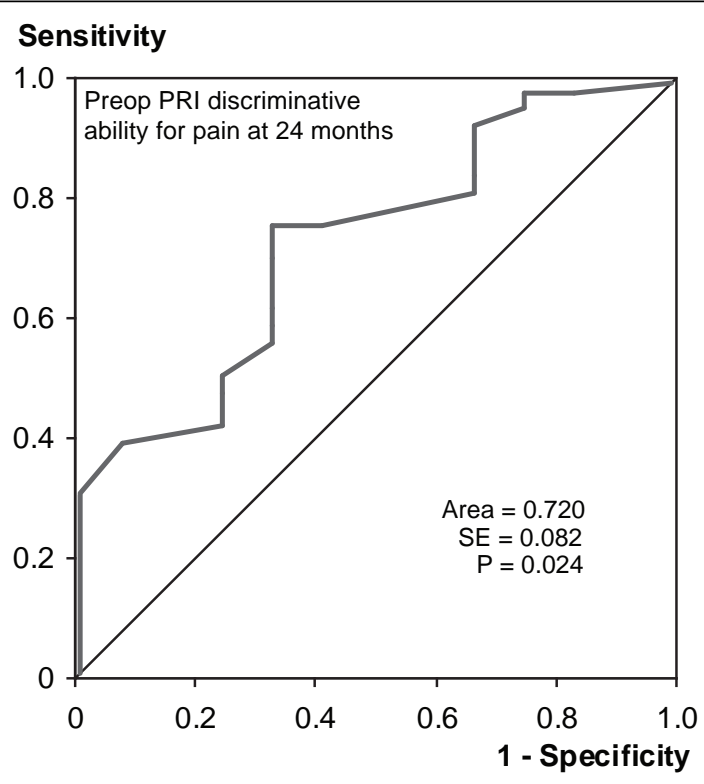

Figure 3) Receiver operating characteristic curve indicating the ability of the preoperative (preop) Pain Rating Index (PRI) scores to discriminate between patients with pain $(n=36)$ and no pain $(n=12)$ at 24 months after surgery, as reported on the PRI

VAS score was 6.8 and decreased to 3.3 after three months, 2.7 after 12 months and 2.2 after 24 months. There were no statistically significant differences among any of the follow-up period PRI or VAS scores, indicating that after three months, reductions in pain had reached a plateau.

Using repeated measures ANOVA tests, it was found that the PCS-T scores did not change significantly between the preoperative and follow-up time periods $(\mathrm{P}>0.05)$. The mean preoperative PCS-T score was 9.8. The mean PCS-T was 10.0 after three months, 8.8 after 12 months and 9.8 after 24 months. The PCS-R, PCS-M and PCS-H scores also remained unchanged despite surgical intervention.

\section{Predictive analyses}

The pain outcome data were skewed, and violated the assumptions of parametric statistical analysis. Therefore, nonparametric ROC curves were used to examine the discriminative and predictive ability of preoperative pain, preoperative catastrophizing scores and comorbidities on postoperative pain outcomes. The pain outcomes at 24 months were chosen as the dependent variable because surgical outcomes stabilized by that time, and the best response rate of our mail-in questionnaires (87\%) was obtained after that period.

ROC curve analysis demonstrated that the preoperative PCS-T score predicted individuals who still had pain according to the PRI at 24 months (Figure 1). The area under the curve was $0.713(\mathrm{P}<0.05)$. Preoperative PCS-R scores predicted PRI scores at 24 months, with an area under the curve of $0.696(\mathrm{P}<0.05)$ (Figure 2). Preoperative PCS-M and PCS-H scores did not provide significant discrimination of pain outcomes. Preoperative PRI scores also predicted the patients who would report pain at 24 months according to the PRI, with an area under the curve of $0.720(\mathrm{P}<0.05)$ (Figure 3$)$. The absolute number of comorbidities predicted the presence of 
TABLE 4

Demographics and preoperative and catastrophizing Pain Rating Index (PRI) scores for pain and no pain groups at 24 months postsurgery

\begin{tabular}{|c|c|c|c|c|c|c|}
\hline & $\begin{array}{c}\text { No pain }(n=12) \\
P R I=0\end{array}$ & $\begin{array}{l}\text { Pain }(n=36) \\
\text { PRI }>0\end{array}$ & $\begin{array}{l}\text { Mann-Whitney } \\
\text { U test }\end{array}$ & $\begin{array}{l}\text { Area under } \\
\text { ROC curve }\end{array}$ & $\begin{array}{l}95 \% \mathrm{CI} \text { for } \\
\text { ROC curve }\end{array}$ & $\begin{array}{c}\text { Asymptomatic } \\
\text { significance ROC curve }\end{array}$ \\
\hline Age, years & $69.2 \pm 7.6$ & $69.6 \pm 7.9$ & $P=0.551$ & - & - & $P>0.10$ \\
\hline Comorbidities, $\mathrm{n}$ & $1.9 \pm 1.2$ & $2.0 \pm 1.5$ & $P=0.971$ & - & - & $P>0.10$ \\
\hline Preoperative PRI & $13.5 \pm 6.3$ & $19.6 \pm 8.1$ & $P=0.023$ & 0.72 & $0.56-0.88$ & $P=0.02$ \\
\hline Preoperative VAS & $6.5 \pm 2.0$ & $6.9 \pm 1.9$ & $P=0.576$ & - & - & $P>0.10$ \\
\hline Preoperative PPI & $2.6 \pm 1.1$ & $2.9 \pm 1.0$ & $P=0.380$ & - & - & $P>0.10$ \\
\hline Preoperative PCS-M & $0.4 \pm 0.7$ & $1.8 \pm 2.5$ & $P=0.098$ & - & - & $P>0.10$ \\
\hline Preoperative PCS-H & $1.3 \pm 1.5$ & $3.9 \pm 5.2$ & $P=0.334$ & - & - & $P>0.10$ \\
\hline Preoperative PCS-T & $4.9 \pm 3.5$ & $11.4 \pm 9.8$ & $P=0.028$ & 0.71 & $0.56-0.87$ & $P=0.03$ \\
\hline
\end{tabular}

Results presented as mean \pm SD unless otherwise stated. PCS-H Pain Catastrophizing Scale - Helplessness; PCS-M Pain Catastrophizing Scale - Magnification PCS-R Pain Catastrophizing Scale - Rumination; PCS-T Pain Catastrophizing Scale - Total; PPI Present pain intensity; ROC Receiver operating characteristic, VAS Visual analogue scale

\section{TABLE 5}

Demographics and preoperative and catastrophizing scores for pain and no pain groups based on the visual analogue scale (VAS) of the McGill Pain Questionnaire at 24 months postsurgery

\begin{tabular}{|c|c|c|c|c|c|c|}
\hline & $\begin{array}{c}\text { No pain }(n=11) \\
\text { VAS }=0\end{array}$ & $\begin{array}{c}\text { Pain }(n=37) \\
\text { VAS }>0\end{array}$ & $\begin{array}{l}\text { Mann-Whitney } \\
\text { U test }\end{array}$ & $\begin{array}{l}\text { Area under } \\
\text { ROC curve }\end{array}$ & $\begin{array}{l}95 \% \mathrm{Cl} \text { for } \\
\text { ROC curve }\end{array}$ & $\begin{array}{c}\text { Asymptomatic } \\
\text { significance ROC curve }\end{array}$ \\
\hline Age, years & $72.2 \pm 8.1$ & $68.6 \pm 7.6$ & $P=0.280$ & - & - & $P>0.10$ \\
\hline Comorbidities, $\mathrm{n}$ & $1.2 \pm 1.0$ & $2.2 \pm 1.4$ & $P=0.029$ & 0.71 & $0.56-0.87$ & $P=0.033$ \\
\hline Preoperative PRI & $14.5 \pm 7.2$ & $19.1 \pm 8.1$ & $P=0.105$ & - & - & $P>0.10$ \\
\hline Preoperative VAS & $6.1 \pm 2.0$ & $7.0 \pm 1.9$ & $P=0.220$ & - & - & $P>0.10$ \\
\hline Preoperative PPI & $2.6 \pm 1.3$ & $2.9 \pm 0.9$ & $P=0.379$ & - & - & $P>0.10$ \\
\hline Preoperative PCS-M & $1.5 \pm 2.3$ & $1.4 \pm 2.3$ & $P=0.668$ & - & - & $P>0.10$ \\
\hline Preoperative PCS-H & $1.6 \pm 1.8$ & $3.7 \pm 5.1$ & $P=0.561$ & - & - & $P>0.10$ \\
\hline Preoperative PCS-T & $7.5 \pm 6.0$ & $10.4 \pm 9.6$ & $P=0.694$ & - & - & $P>0.10$ \\
\hline
\end{tabular}

Results presented as mean \pm SD unless otherwise stated. PCS-H Pain Catastrophizing Scale - Helplessness; PCS-M Pain Catastrophizing Scale - Magnification; PCS-R Pain Catastrophizing Scale - Rumination; PCS-T Pain Catastrophizing Scale - Total; PPI Present pain intensity; PRI Pain rating index; ROC Receiver operating characteristic

pain as rated by the VAS at 24 months (Figure 4). The area under the curve was $0.714(\mathrm{P}<0.05)$.

To confirm the ROC curve analyses, patients with persistent pain (PRI $>0 ; n=36)$ and no pain (PRI=0; $=12$ ) at 24 months according to the PRI were compared using the nonparametric Mann-Whitney U test (Table 4). Because ROC curves are based on sensitivity and specificity, the sample was dichotomized into definitive 'pain' and 'no pain' groups, rather than arbitrarily dichotomizing the population as having mild or moderate pain. Patients with persistent pain at 24 months had significantly higher preoperative PCS-R scores (5.6 versus 3.3, $\mathrm{P}<0.05)$, PCS-T scores (11.4 versus $4.9, \mathrm{P}<0.05)$ and PRI scores $(19.6$ versus $13.5, \mathrm{P}<0.05)$. There were no significant differences in age, sex or length of hospital stay between these two groups. Those patients with and without pain at 24 months, as measured on the VAS, were compared using the Mann-Whitney U test (Table 5). Patients with persistent pain at 24 months had a significantly higher number of comorbidities $(2.2$ versus $1.2, \mathrm{P}<0.05)$. No other differences between the no pain and the persistent pain groups could account for the observed difference in preoperative comorbidities.

\section{DISCUSSION}

As expected, there was a dramatic decrease in pain scores after TKA. The pain scores decreased significantly within the first

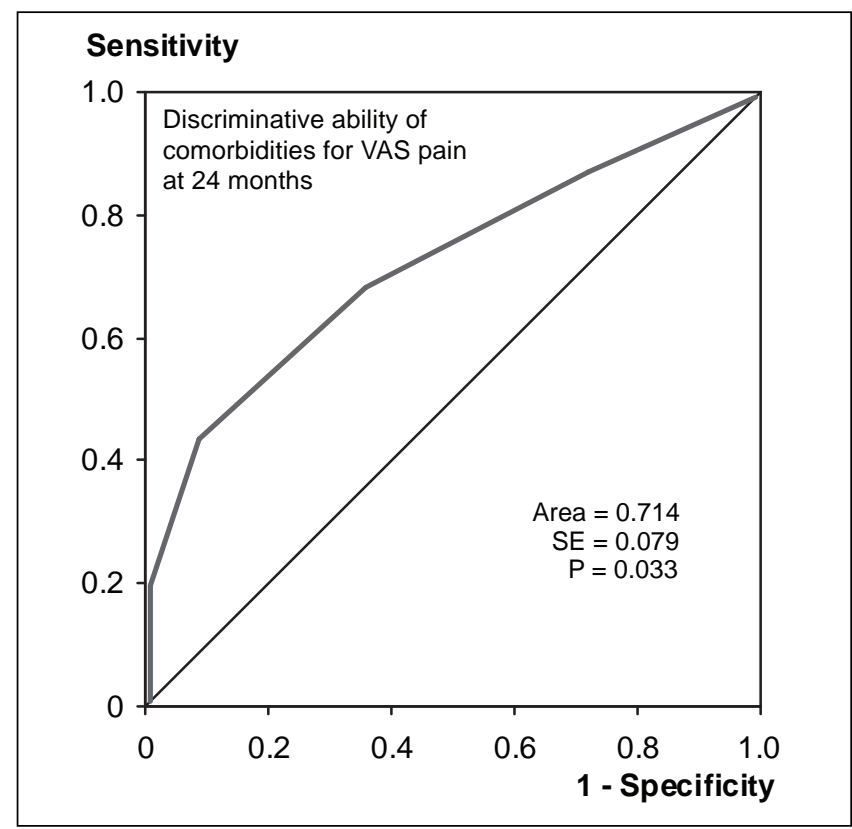

Figure 4) Receiver operating characteristic curve indicating the ability of comorbidities (extracted from chart data) to discriminate between patients with pain $(n=37)$ and no pain $(n=11)$ at 24 months after surgery, as reported on the visual analogue scale (McGill Pain Questionnaire). 
three months postoperatively, and continued to decrease over the next two years at a slower rate, reaching a final plateau. This was in keeping with previous literature, using standard validated outcome questionnaires, in that the standardized effect size for the outcome of TKA is large and occurs shortly after surgery (10). The remainder of the subjective improvement occurs over a two-year interval, at which time a plateau is reached on the timeline graph (4).

Our predictive analyses demonstrated that initial pain, as measured by the PRI, predicted which patients had a worse pain outcome after 24 months. This is consistent with other pain literature that reported presurgical pain is a significant determinant of postsurgical physical and emotional distress (5). It is interesting to note that heightened pain presurgery is often a consequence of the prolonged waiting times associated with TKA (33). Prolonged waiting times may be the result of hospital wait lists, or surgeon-specific preferences to delay surgery for as long as patients can tolerate their pain. Patients with increased wait times for TKA and worsening preoperative pain may have a worse outcome after surgery (34).

Furthermore, we found that a psychological variable, catastrophizing, did not significantly change after TKA. This would suggest that catastrophizing may be a trait-like variable that remains stable unless specific psychological intervention also takes place (22). The PCS-R was the best predictor of the PRI subscale of the MPQ. This may be related to the increased attention and consequent increased sensory flow of pain signals. Attention to pain symptoms has been discussed as a possible mechanism contributing to altered central thresholds of excitability, or the amplification of pain signals (35). As a function of the tendency to focus excessively on pain sensations, catastrophizers' central neural mechanisms may become more sensitized, yielding a chronic hyperalgesic state $(22)$.

The only other variable that affected postoperative pain outcomes was the number of preoperative comorbidities the patient had. There is a heavier psychological burden on patients

\section{REFERENCES}

1. Arden N, Nevitt MC. Osteoarthritis: Epidemiology. Best Pract Res Clin Rheumatol 2006;20:3-25.

2. Issa SN, Sharma L. Epidemiology of osteoarthritis: An update. Curr Rheumatol Rep 2006;8:7-15.

3. Brander VA, Stulberg SD, Adams AD, et al. Predicting total knee replacement pain: A prospective, observational study. Clin Orthop Relat Res 2003:27-36.

4. Lingard EA, Katz JN, Wright EA, Sledge CB; for the Kinemax Outcomes Group. Predicting the outcome of total knee arthroplasty. J Bone Joint Surg Am 2004;86-A:2179-86.

5. Fortin PR, Clarke AE, Joseph L, et al. Outcomes of total hip and knee replacement: Preoperative functional status predicts outcomes at six months after surgery. Arthritis Rheum 1999;42:1722-8.

6. Robertsson O, Dunbar M, Pehrsson T, Knutson K, Lidgren L. Patient satisfaction after knee arthroplasty: A report on 27,372 knees operated on between 1981 and 1995 in Sweden. Acta Orthop Scand 2000;71:262-7.

7. Arnett G, Hadorn DC; for the Steering Committee of the Western Canada Waiting List Project. Developing priority criteria for hip and knee replacement: Results from the Western Canada Waiting List Project. Can J Surg 2003;46:290-6.

8. Brandt KD. The importance of nonpharmacologic approaches in management of osteoarthritis. Am J Med 1998;105:39S-44S.

9. Yercan HS, Sugun TS, Bussiere C, Ait Si Selmi T, Davies A, Neyret P. Stiffness after total knee arthroplasty: Prevalence, management and outcomes. Knee 2006;13:111-7.

10. Dunbar MJ. Subjective outcomes after knee arthroplasty. Acta Orthop Scand Suppl 2001;72:1-63. with multiple medical problems, and this may lead to altered pain experiences when compared with patients who suffer from isolated OA of the knee (36). There is some support in the current literature for this hypothesis, although further research is needed to clarify this $(36,37)$.

The modest sample size of the present study calls for caution in the interpretation of findings. Although separate analyses were conducted to assess the predictive value of preoperative pain, pain catastrophizing and comorbidities, it is clear that these variables interact with each other and have an impact on pain outcomes. The present sample was not sufficiently large to permit examination of summative or interactive effects of these variables. A larger scale study is planned to address these issues in the near future.

Another potential weakness of the present study is the lack of pain measures in the perioperative period. However, this was not the main focus because immediate postoperative pain is almost entirely related to surgery itself, and is compounded by the use of postoperative pain management protocols. We chose to focus on the persistence of pain after healing of the surgical site to determine the final long-term pain-related outcome. The relation between immediate postoperative pain and its management, and long-term persistent pain should be addressed in future studies.

Increased attention to psychological factors in orthopedic surgery, specifically TKA, may lead to better outcomes, including pain management and quality of life (38). When patients were asked what concerned them the most following surgery, they said it was the postoperative pain experience (39). The major clinical implication of this study is that a preoperative self-administered questionnaire may help identify a group of 'high-risk' patients for persistent pain after TKA. Preoperative interventions to reduce catastrophic thinking in these patients may help reduce their pain following surgery. Other preoperative interventions have already been shown to decrease the amount of perioperative anxiety that patients experience, and may lead to improved outcomes (40).

11. Ryd L, Kärrholm J, Ahlvin P. Knee scoring systems in gonarthrosis. Evaluation of interobserver variability and the envelope of bias. Score Assessment Group. Acta Orthop Scand 1997;68:41-5.

12. Harden RN, Bruehl S, Stanos S, et al. Prospective examination of pain-related and psychological predictors of CRPS-like phenomena following total knee arthroplasty: A preliminary study. Pain 2003;106:393-400.

13. Long WT, Ward SR, Dorr LD, Raya J, Boutary M, Sirianni LE. Postoperative pain management following total knee arthroplasty: A randomized comparison of continuous epidural versus femoral nerve infusion. J Knee Surg 2006;19:137-43.

14. Ackerman IN, Graves SE, Wicks IP, Bennell KL, Osborne RH. Severely compromised quality of life in women and those of low socioeconomic status waiting for joint replacement surgery. Arthritis Rheum 2005;53:653-8.

15. Wright WL. Osteoarthritis management today: Minimizing pain and maximizing quality of life. Adv Nurse Pract 2004;12:24-9.

16. Turk DC, Okifuji A. Psychological factors in chronic pain: Evolution and revolution. J Consult Clin Psychol 2002;70:678-90.

17. Keefe FJ, Abernethy AP, Campbell LC. Psychological approaches to understanding and treating disease-related pain. Annu Rev Psychol 2005;56:601-30.

18. Keefe FJ, Caldwell DS, Queen K, et al. Osteoarthritic knee pain: A behavioral analysis. Pain 1987;28:309-21.

19. Keefe FJ, Rumble ME, Scipio CD, Giordano LA, Perri LM. Psychological aspects of persistent pain: Current state of the science. J Pain 2004;5:195-211. 
20. Turk D. Biopsychosocial perspective on chronic pain. In: Gatchel RJ, Turk DC, eds. Psychological Approaches to Pain Management: A Practitioner's Handbook. New York: Guilford Press, 1996

21. Sullivan MJ, Bishop SR, Pivik J. The Pain Catastrophizing Scale: Development and validation. Psychol Assess 1995;7:524-32.

22. Sullivan MJ, Thorn B, Haythornthwaite JA, et al. Theoretical perspectives on the relation between catastrophizing and pain. Clin J Pain 2001;17:52-64.

23. Leeuw M, Goossens ME, Linton SJ, Crombez G, Boersma K, Vlaeyen JW. The fear-avoidance model of musculoskeletal pain: Current state of scientific evidence. J Behav Med 2007;30:77-94.

24. Sullivan MJ, Feuerstein M, Gatchel R, Linton SJ, Pransky G. Integrating psychological and behavioral interventions to achieve optimal rehabilitation outcomes. J Occup Rehabil 2005;15:475-89.

25. Roth ML, Tripp DA, Harrison MH, Sullivan M, Carson P. Demographic and psychosocial predictors of acute perioperative pain for total knee arthroplasty. Pain Res Manage 2007;12:185-94.

26. Pincus T, Burton AK, Vogel S, Field AP. A systematic review of psychological factors as predictors of chronicity/disability in prospective cohorts of low back pain. Spine 2002;27:E109-20.

27. Linton SJ. Do psychological factors increase the risk for back pain in the general population in both a cross-sectional and prospective analysis? Eur J Pain 2005;9:355-61.

28. Jellema P, van der Horst HE, Vlaeyen JW, Stalman WA, Bouter LM, van der Windt DA. Predictors of outcome in patients with (sub)acute low back pain differ across treatment groups. Spine 2006;31:1699-705

29. Edwards RR. Genetic predictors of acute and chronic pain. Curr Rheumatol Rep 2006;8:411-7.

30. Shipton E. Predictors of persistent acute postoperative pain: an opportunity for preventative medicine to reduce the burden of chronic pain. NZ Med J 2005;118:U1261.
31. Kovacs FM, Abraira V, Zamora J, Fernández C; for the Spanish Back Pain Research Network. The transition from acute to subacute and chronic low back pain: A study based on determinants of quality of life and prediction of chronic disability. Spine 2005;30:1786-92.

32. Melzack R. The short-form McGill Pain Questionnaire. Pain 1987;30:191-7.

33. Fortin PR, Penrod JR, Clarke AE, et al. Timing of total joint replacement affects clinical outcomes among patients with osteoarthritis of the hip or knee. Arthritis Rheum 2002:46:3327-30

34. Lynch ME, Campbell F, Clark AJ, et al. A systematic review of the effect of waiting for treatment for chronic pain. Pain 2008; 136:97-116.

35. Crombez G, Eccleston C, Baeyens F, Eelen P. When somatic information threatens, catastrophic thinking enhances attentional interference. Pain 1998;75:187-98.

36. Wasielewski RC, Weed H, Prezioso C, Nicholson C, Puri RD. Patient comorbidity: Relationship to outcomes of total knee arthroplasty. Clin Orthop Relat Res 1998:85-92.

37. Rosemann T, Grol R, Herman K, Wensing M, Szecsenyi J. Association between obesity, quality of life, physical activity and health service utilization in primary care patients with osteoarthritis. Int J Behav Nutr Phys Act 2008;5:4

38. Lingard EA, Riddle DL. Impact of psychological distress on pain and function following knee arthroplasty. J Bone Joint Surg Am 2007;89:1161-9.

39. Trousdale RT, McGrory BJ, Berry DJ, Becker MW, Harmsen WS. Patients' concerns prior to undergoing total hip and total knee arthroplasty. Mayo Clin Proc 1999;74:978-82.

40. Bondy LR, Sims N, Schroeder DR, Offord KP, Narr BJ. The effect of anesthetic patient education on preoperative patient anxiety. Reg Anesth Pain Med 1999;24:158-64. 


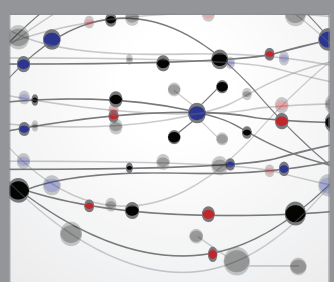

The Scientific World Journal
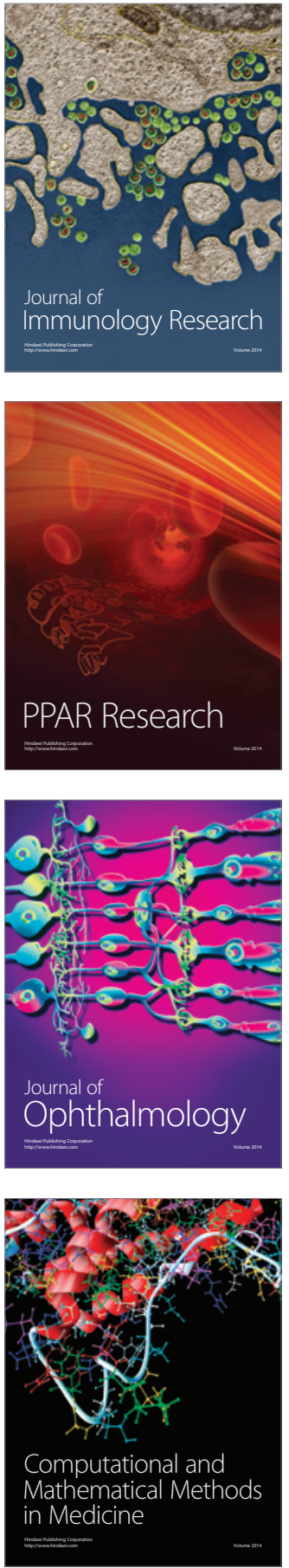

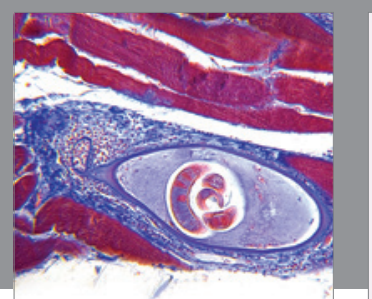

Gastroenterology Research and Practice

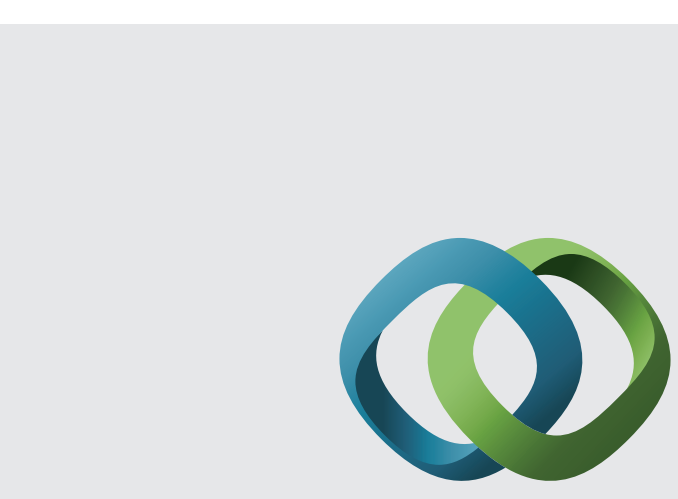

\section{Hindawi}

Submit your manuscripts at

http://www.hindawi.com
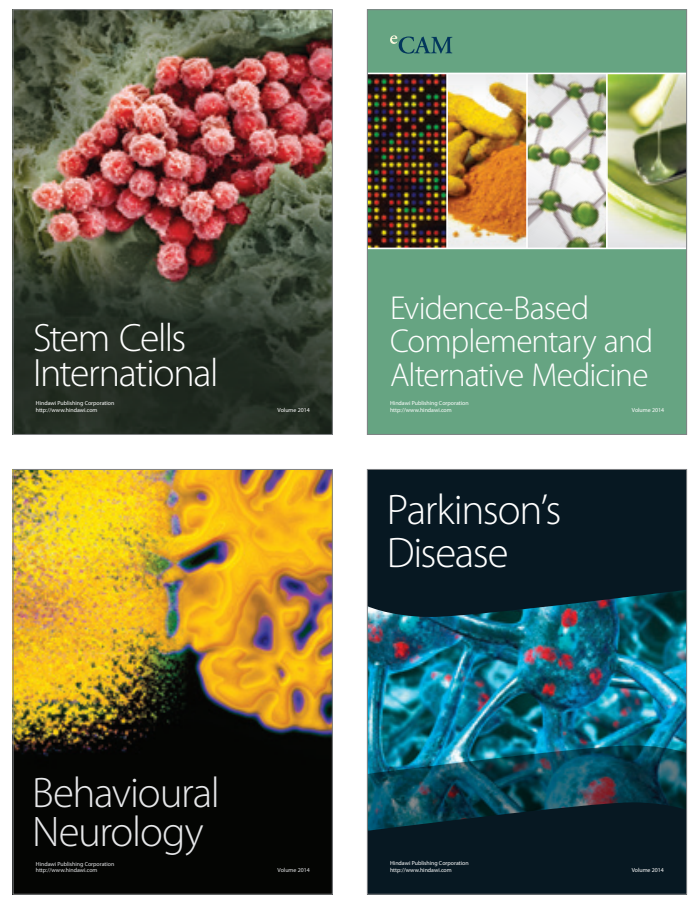
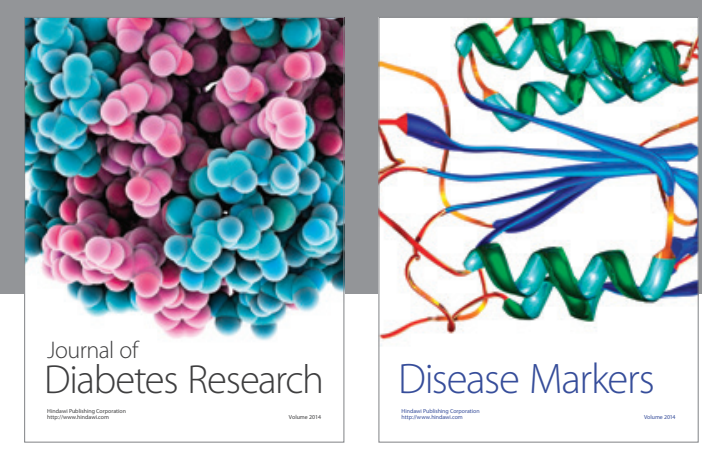

Disease Markers
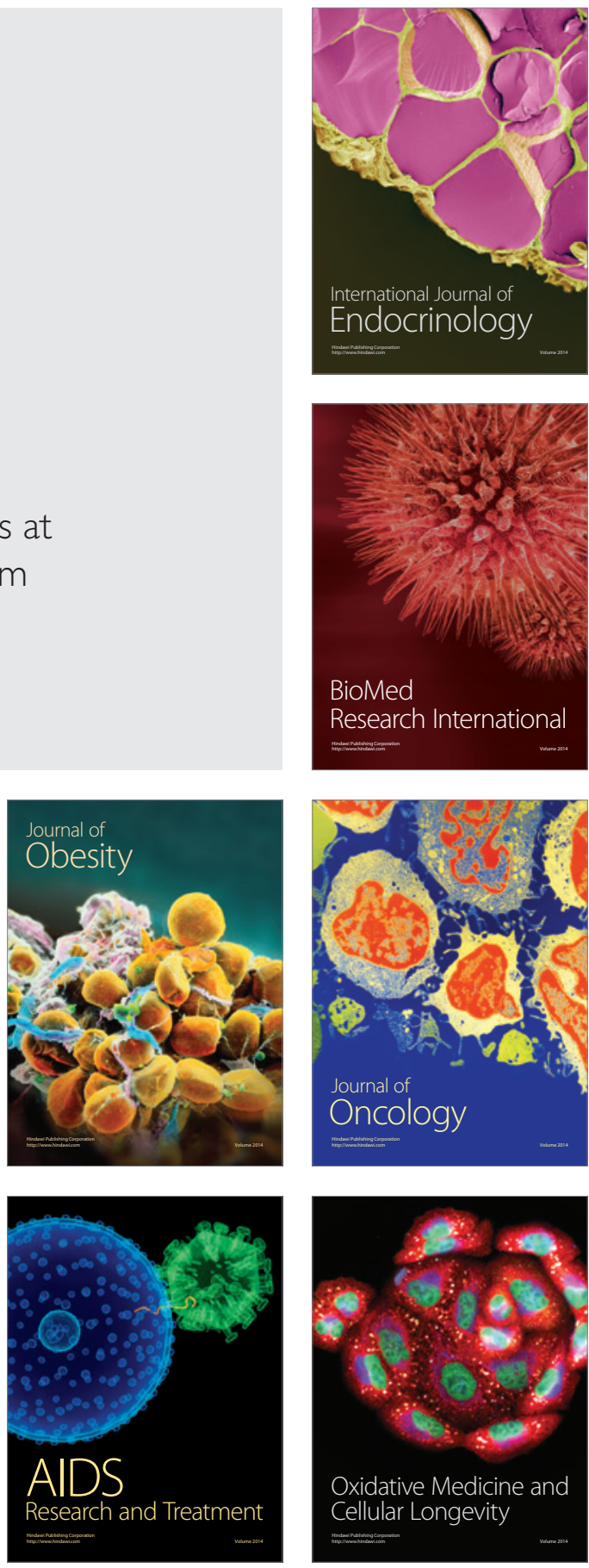